\title{
XAV939 inhibits the proliferation and migration of lung adenocarcinoma A549 cells through the WNT pathway
}

\author{
CHONG LI" ${ }^{*}$ XU ZHENG* ${ }^{*}$ YANYAN HAN, YAN LV, FU LAN and JIE ZHAO \\ Department of Pathology, First Teaching Hospital of Tianjin University of Traditional Chinese Medicine, \\ Tianjin 300000, P.R. China
}

Received November 15, 2016; Accepted October 26, 2017

DOI: $10.3892 / \mathrm{ol} .2018 .8491$

\begin{abstract}
The present study assessed the effects of the tankyrase (TNKS) small molecule inhibitor XAV939 on the proliferation and migration of lung adenocarcinoma A549 cells and the possible underlying mechanism. To do this, the association between TNKS and the WNT/ $\beta$-catenin signaling pathway in lung acinar adenocarcinoma was investigated. Immunohistochemistry was performed, which demonstrated that TNKS, $\beta$-catenin and Myc proto-oncogene protein (c-Myc) proteins are positively expressed in lung adenocarcinoma tissue; this expression was significantly higher than that in normal adjacent non-carcinoma tissues. A549 cell proliferation was inhibited in all XAV939-intervention groups examined. In the wound-healing assay, cells treated with different concentrations of XAV939 exhibited a significantly increased scratch width compared with the control group. Reverse transcription-semi-quantitative polymerase chain reaction analysis revealed that $\beta$-catenin mRNA expression was significantly decreased in A549 cells in response to different XAV939 concentrations compared with the control group. Immunofluorescence revealed that $\beta$-catenin protein, initially localized in the nucleus/cytoplasm, gradually translocated to the cytoplasm/membrane, an effect that was associated with increased drug concentration. TNKS, $\beta$-catenin and c-Myc protein expression in A549 cells treated with XAV939 was reduced compared with that in untreated cells. Therefore, abnormally high TNKS expression may promote the occurrence of lung cancer. The TNKS inhibitor XAV939 inhibited lung adenocarcinoma A549 cell proliferation and migration in vitro. The underlying mechanism by which XAV939 exerted
\end{abstract}

Correspondence to: Dr Chong Li, Department of Pathology, First Teaching Hospital of Tianjin University of Traditional Chinese Medicine, 88 Changling Road, Xiqing, Tianjin 300000, P.R. China E-mail:1c740922@163.com

\section{${ }^{*}$ Contributed equally}

Key words: tankyrase, XAV939, lung adenocarcinoma, $\beta$-catenin, WNT signaling pathway its inhibitory effects may be associated with attenuation of the WNT signaling pathway.

\section{Introduction}

Lung cancer is one of the leading causes of cancer-associated mortality worldwide, resulting in $>1$ million deaths annually (1). Non-small cell lung carcinoma (NSCLC) accounts for $\sim 85 \%$ of lung cancer cases (2). As an antitumor drug, cisplatin (DDP) is commonly used for non-small cell lung cancer as a first-line treatment (3); however, this treatment is associated with serious adverse side effects. Hence, the identification of novel target drugs or an effective combination of existing drugs is required for the improved treatment of lung cancer.

The WNT signaling pathway serves a key role in the regulation of cell proliferation, differentiation, apoptosis and migration. Abnormal expression and activation of WNT signaling pathway components have been observed to induce tumorigenesis $(4,5)$. Tankyrase (TNKS) is an important regulator of canonical WNT/ $\beta$-catenin signaling (6). TNKS was initially discovered to bind with telomerase repeat binding sequences and belongs to the family of proteins responsible for poly ADP-ribosylation (PARylation), which includes TNKS1 and TNKS2 (6). Busch et al (7) demonstrated that TNKS-knockdown reduced the proliferation of murine and human lung cancer cell lines, and decreased tumor formation in mouse models. TNKS inhibition may therefore represent a novel therapeutic strategy for cancer treatment. XAV939 is a small molecule that selectively inhibits TNKS family members, including TNKS1 and TNKS2. XAV939 can inhibit the transcription regulated by $\beta$-catenin, which is a key transcription factor in the WNT signaling pathway. Kulak et al (8) revealed that XAV939 inhibited the activation of $\beta$-catenin; after binding to TNKS, XAV939 was able to stimulate $\beta$-catenin phosphorylation and abolish the function of axin in the 'destruction complex'. This action resulted in the inhibition of the WNT pathway and stabilization of axin by PARylation $(9,10)$. Targeting components of the WNT-TNKS- $\beta$-catenin pathway, together with epidermal growth factor receptor (EGFR) inhibition, may improve clinical outcomes in patients with NSCLC (11). Through its effect on TNKS activity, XAV939 also inhibited WNT signaling in cancer of the breast, colon and other tissues (12). However, XAV939-mediated regulation of the WNT signaling pathway 
in lung cancer has not been clearly elucidated. Therefore, the aim of the present study was to investigate whether different concentrations of XAV939 influenced the proliferation and migration of the lung adenocarcinoma A549 cell line, via with the WNT signaling pathway. The present study demonstrated that TNKS (TNKS1 and TNKS2) and $\beta$-catenin expression were increased in lung adenocarcinoma and that this increase positively correlated with expression of the other. It is hoped that the present study provides a novel approach and experimental evidence for the basis for the future clinical treatment of lung cancer.

\section{Materials and methods}

Patient samples. The present study consisted of 72 patients (including 37 men and 35 women; 34-83 years old, with a mean age of $61.24 \pm 3.56)$ with single-subtype alveolar-like lung adenocarcinoma (the lung adenocarcinoma group) and 67 patients (including 34 men and 33 women; 34-78 years old, with a mean age of $60.44 \pm 4.23$ ) with normal lung tissue adjacent to carcinoma specimens (the adjacent-to-carcinoma group) who underwent lung adenocarcinoma puncture and bronchoscopy between January 2011 and June 2015. Formalin-fixed and paraffin-embedded patient samples were obtained from the Department of Pathology at First Teaching Hospital of Tianjin University of Traditional Chinese Medicine (Tianjin, China). Sections from all cases were reviewed and confirmed to be single-subtype alveolar-like lung adenocarcinoma by two senior pathologists affiliated with the First Teaching Hospital of Tianjin University of Traditional Chinese Medicine.

All patients were diagnosed with lung cancer and had no indication of surgery, nor had any undergone chemotherapy or radiotherapy. Retrospective clinicopathological data, including age, gender and degree of cancer cell differentiation, were also obtained from the patients. A total of 21 pairs of single subtype alveolar-like lung adenocarcinoma samples and matched adjacent normal lung tissues (including 11 men and 10 women; 33-78 years old, with a mean age of $60.23 \pm 3.44$ ) were selected following lung puncture and bronchoscopy between January 2014 and June 2015 , and frozen in liquid nitrogen at $-80^{\circ} \mathrm{C}$, within $20 \mathrm{~min}$ of collection. The use of the tissue samples for this study was approved by the First Teaching Hospital of Tianjin University of Traditional Chinese Medicine Medical Ethics Committee.

Reagents. The primary antibodies used were mouse anti-tankyrase (cat no. ab13587; Abcam, Cambridge, UK), mouse anti- $\beta$-catenin (cat no. ZS-7963; OriGene Technologies, Inc., Beijing, China) and mouse anti- $\beta$-actin (cat no. MAB8929; OriGene Technologies, Inc.), mouse anti-Myc proto-oncogene protein (c-Myc) (cat no. sc-40; Santa Cruz Biotechnology, Inc., Dallas, TX, USA).

Immunohistochemistry (IHC). Formalin-fixed and paraffin-embedded sections were deparaffinized by sequential washing with xylene, and graded ethanol (100, 95, 80 and 70\%), and subsequently heated with sodium citrate buffer $0.01 \mathrm{M}$, pH 6.0 in a pressure cooker to $\sim 95^{\circ} \mathrm{C}$ for $2 \mathrm{~min}$ to perform antigen retrieval. The sections were incubated with $3 \% \mathrm{H}_{2} \mathrm{O}_{2}$ in methanol for $15 \mathrm{~min}$ at $25^{\circ} \mathrm{C}$, blocked using goat isolated serum for $30 \mathrm{~min}$ at $25^{\circ} \mathrm{C}$, and then incubated with mouse anti-TNKS monoclonal antibody (1:200 dilution), mouse anti- $\beta$-catenin monoclonal antibody (1:200 dilution), and mouse anti-cMyc monoclonal antibody (1:100 dilution), overnight, at $4^{\circ} \mathrm{C}$. The slides were then incubated with horseradish peroxidase-conjugated goat anti-rabbit/mouse secondary antibodies (cat no. PV9000; OriGene Technologies, Inc.) at $37^{\circ} \mathrm{C}$ for $30 \mathrm{~min}$. Samples known to express TNKS, $\beta$-catenin, and c-Myc, among others, served as positive control, whereas PBS was used instead of the primary antibody as negative control. Positive samples were obtained from the Department of Pathology, First Teaching Hospital of Tianjin University of Traditional Chinese Medicine. The intensity of staining was evaluated using the following criteria: 1 , negative; 2 , positive (brown). The extent of staining was scored as $0,0 \%$ of cells stained; $1,1-25 \%$ stained; 2, 26-50\% stained; 3, 51-100\% stained. The final score was calculated by multiplying the intensity score by the extent score. The staining results were divided into two categories, according to the final score: $<3$, negative, $\geq 3$, positive. If $10 \%$ of cancer cells were positive for nuclear staining, they were defined as positive.

Cell culture. The human A549, Calu-3 and SK-LU-1 cells were provided by Dr Shiwu Zhang (Tianjin Union Medicine Center, Nankai University Affiliated Hospital, Tianjin, China). Cells were maintained in RPMI-1640 medium (Hyclone; GE Healthcare, Chicago, IL, USA), supplemented with $10 \%$ (v/v) fetal bovine serum (Hyclone) and cultured in a humidified incubator with $5 \% \mathrm{CO}_{2}$ at $37^{\circ} \mathrm{C}$.

MTT cell viability assay. A549 cells in the logarithmic growth phase were seeded in 96-well plates, at a density of $2 \times 10^{4}$ cells/well, and subsequently treated with various XAV939 (Selleck Chemicals, Houston, TX, USA) concentrations $(0.1,0.5,1,5,10 \mu \mathrm{mol} / \mathrm{l})$ for $24,48,72$ and $96 \mathrm{~h}$. MTT was added to the cells $4 \mathrm{~h}$ prior to harvesting. Cells from each group were incubated for $4 \mathrm{~h}$ with $10 \mu \mathrm{l}$ MTT, which was subsequently replaced by $150 \mu \mathrm{l}$ DMSO. The 96-well plates were then placed on a shaking table for $10 \mathrm{~min}$. Cell viability was determined by colorimetry, and measured the absorbance using a microplate reader (Thermo Fisher Scientific, Inc., Waltham, MA, USA) at a wavelength of $490 \mathrm{~nm}$ (A490 value).

Colony formation assay. For the colony formation assays, A549 cells were plated at a density of 200 cells/well in 6-well tissue culture plates (Corning Incorporated, Corning, NY, USA) in triplicate for $24 \mathrm{~h}$ prior to drug (XAV939; Selleck Chemicals) or control treatments. After 24 h, A549 cells were treated with doses of $0.1,1,10 \mu \mathrm{mol} / 1$ XAV939. After $48 \mathrm{~h}$ of culture in treatment, the colonies were fixed with $4 \%$ paraformaldehyde for $15 \mathrm{~min}$ at $25^{\circ} \mathrm{C}$, stained with $0.5 \%$ crystal violet solution for $20 \mathrm{~min}$ at $25^{\circ} \mathrm{C}$, and four fields of view were counted. The level of colony formation was observed using an inverted light microscope.

Wound healing assay. A549 cells were seeded into 6-well plates at a density of $1 \times 10^{5}$ cells/well. After $24 \mathrm{~h}$, a sterilized $200 \mu \mathrm{l}$ pipette tip was used to generate a wound across the cells. Cells migrating into the wounded area were observed at different time points ( 0 and $24 \mathrm{~h})$ under an inverted light 
Table I. Polymerase chain reaction primers used in this study.

\begin{tabular}{|c|c|c|}
\hline Gene & Sequence, 5'-3' & $\begin{array}{c}\text { Product size, } \\
\text { bp }\end{array}$ \\
\hline $\begin{array}{c}\beta \text {-catenin } \\
\text { Forward } \\
\text { Reverse }\end{array}$ & $\begin{array}{l}\text { ATCATTCTGGCCAGTGCTGG } \\
\text { GACAGCACCTTCAGCACTCT }\end{array}$ & 104 \\
\hline $\begin{array}{l}\text { c-Myc } \\
\text { Forward } \\
\text { Reverse }\end{array}$ & $\begin{array}{l}\text { GAGTCAGGGTCATCCCCATCA } \\
\text { CCAAGACGTTGTGTGTCCGC }\end{array}$ & 110 \\
\hline $\begin{array}{l}\beta \text {-actin } \\
\text { Forward } \\
\text { Reverse }\end{array}$ & $\begin{array}{l}\text { TCTGTGTGGATTGGTGGCTCT } \\
\text { AGAAGCATTTGCGGTGCAC }\end{array}$ & 115 \\
\hline
\end{tabular}

c-Myc, Myc proto-oncogene protein.

microscope at a magnification of $\times 200$. A total of 9 fields of view were randomly analyzed in each well.

Reverse transcription-semi-quantitative polymerase chain reaction (RT-PCR). A549 cells were treated with various concentrations of XAV939 $(0.1,1$ and $10 \mu \mathrm{mol} / \mathrm{l})$ for $24 \mathrm{~h}$. Total RNA was extracted from A549 cells using TRIzol (Thermo Fisher Scientific, Inc.) according to the manufacturer's protocol. cDNA was generated using gene-specific random hexamers (Sangon Biotech Co., Ltd, Shanghai, China) (Table I) and RT kit (Tiangen Biotech Co., Ltd., Beijing, China). The PCR reaction conditions were as follows: $95^{\circ} \mathrm{C}$ for $5 \mathrm{~min}$ followed by 40 cycles of $95^{\circ} \mathrm{C}$ for $30 \mathrm{sec}, 60^{\circ} \mathrm{C}$ for $30 \mathrm{sec}, 72^{\circ} \mathrm{C}$ for $30 \mathrm{sec}$ and a final extension step of $72^{\circ} \mathrm{C}$ for $5 \mathrm{~min}$. Samples were then left at $4^{\circ} \mathrm{C}$ until further use. Agarose gel $(1.5 \%)$ was used to run the PCR product which scanned pictures using a gel imaging system (Fluor Corporation, Irving, TX, USA). All data were normalized to endogenous $\beta$-actin, which used as an endogenous control. Image Pro Plus 6.0 software (Media Cybernetics, Inc., Rockville, MD, USA) was applied to analyze the band intensity.

Immunofluorescence. A549 cells were cultured in 24-well plates for $24 \mathrm{~h}$. Once they had adhered to glass slides at $80 \%$ density, cells were divided into four groups: The control group (treated with $\mathrm{NaCl}$ ), and the $0.1,1$ and $10 \mu \mathrm{mol} / 1$ XAV939 treatment groups. After $48 \mathrm{~h}$ of treatment, cells were fixed with $4 \%$ paraformaldehyde for $15 \mathrm{~min}$ at $25^{\circ} \mathrm{C}$. Cells were incubated with $0.5 \%$ Triton X-100 (PBS compound) for $20 \mathrm{~min}$ at $25^{\circ} \mathrm{C}$ and blocked using goat isolated serum (cat no. ZLI-9022; OriGene Technologies, Inc.), for $30 \mathrm{~min}$ at $25^{\circ} \mathrm{C}$. Then, cells were incubated with a monoclonal antibody against $\beta$-catenin $(1: 100)$, at $4^{\circ} \mathrm{C}$ overnight. The following day, a FITC-conjugated goat anti mouse $\operatorname{IgG}(1: 100$; cat no. ZF0312; OriGene Technologies, Inc.) secondary antibody was added, and cells were incubated in the dark for $60 \mathrm{~min}$ at $37^{\circ} \mathrm{C}$. DAPI was used to counterstain the nuclei for $5 \mathrm{~min}$ at $25^{\circ} \mathrm{C}$. Positive and negative control groups were also prepared and images were captured using a fluorescence microscope (at a magnification of $\mathrm{x} 200$ ).
Western blot analysis. A total of 21 pairs of lung adenocarcinoma samples and adjacent normal lung tissues were lysed in SDS lysis buffer. (Beyotime Institute of Biotechnology, Shanghai, China). The protein concentration was measured using a BCA Protein Assay kit (Beyotime Institute of Biotechnology). A total of $40 \mu \mathrm{g}$ protein lysates were separated by SDS-PAGE (10\%) and transferred by electrophoresis to polyvinylidene difluoride (PVDF) membranes. The membranes were blocked with $5 \%$ non-fat milk for $2 \mathrm{~h}$ at room temperature and incubated overnight at $4^{\circ} \mathrm{C}$ with primary antibodies. The target proteins were detected by western blot analysis with the following primary antibodies: Mouse anti-human TNKS monoclonal antibody $(1: 400), \beta$-actin antibody $(1: 2,000)$ overnight at $4^{\circ} \mathrm{C}$. After washing with PBS-Tween-20 (PBST), membranes were incubated with goat anti-mouse horseradish peroxidase-conjugated polyclonal secondary antibodies (cat no. ZDR5307, 1:1,000; OriGene Technologies, Inc.) for $2 \mathrm{~h}$ at $25^{\circ} \mathrm{C}$. Proteins were detected using an enhanced chemiluminescence kit (Tanon Science and Technology Co., Ltd., Shanghai, China). All quantitative data were normalized to $\beta$-actin, which used as an endogenous control. Image Pro Plus 6.0 software (Media Cybernetics, Inc., Rockville, MD, USA) was applied to analyze the band intensity.

A549, Calu-3 and SK-LU-1 cells were lysed with ice-cold RIPA buffer (Beyotime Institute of Biotechnology, Shanghai, China), and protein concentrations were determined by BCA method. Equal amounts of $40 \mu \mathrm{g}$ protein lysates were separated by SDS-PAGE (10\%) and then transferred to PVDF membranes. Membranes were incubated overnight at $4^{\circ} \mathrm{C}$ with the following primary antibodies: Anti-TNKS (1:400), and $\beta$-actin $(1: 2,000)$. After washing with PBST, the corresponding concentrations of goat anti-mouse IgG-FITC secondary antibody (cat no. ZDR5307; 1:1,000; OriGene Technologies, Inc.) was joined for $2 \mathrm{~h}$ at $25^{\circ} \mathrm{C}$. Proteins were detected using an enhanced chemiluminescence kit (Tanon Science and Technology Co., Ltd). All quantitative data were normalized to $\beta$-actin, which was used as an endogenous control. Image Pro Plus 6.0 software was applied to analyze the band intensity.

A549 cells were treated with DDP $(0.002 \mathrm{~g} / 1$; approval no. H21020212; Jinzhou Jiutai Pharmaceutical Co., Ltd., Jinzhou, China), $1 \mu \mathrm{mol} / 1 \mathrm{XAV} 939,0.002 \mathrm{~g} / 1 \mathrm{DDP}$ and $1 \mu \mathrm{mol} / 1$ XAV939 for $24 \mathrm{~h}$. Then the cells lysed with ice-cold RIPA buffer (Beyotime Institute of Biotechnology), and protein concentrations were determined by BCA method. Equal amounts of $40 \mu \mathrm{g}$ protein lysates were separated by SDS-PAGE $(10 \%)$ and then transferred to PVDF membranes. Membranes were incubated overnight at $4^{\circ} \mathrm{C}$ with the following primary antibodies: Anti-TNKS (1:400), anti- $\beta$-catenin (1:500), anti-c-Myc (1:500) and $\beta$-actin $(1: 2,000)$. After washing with PBST, the corresponding concentrations of goat anti-mouse IgG-FITC secondary antibody (cat no. ZDR5307; 1:1,000; OriGene Technologies, Inc.) was joined for $2 \mathrm{~h}$ at $25^{\circ} \mathrm{C}$. Proteins were detected using an enhanced chemiluminescence kit (Tanon Science and Technology Co., Ltd). All quantitative data were normalized to $\beta$-actin, which was used as an endogenous control. Image Pro Plus 6.0 software was applied to analyze the band intensity.

Statistical analysis. Data are presented as the mean \pm standard deviation and all statistical analyses were performed using 
A

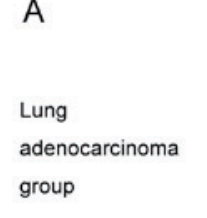

Adjacent

group

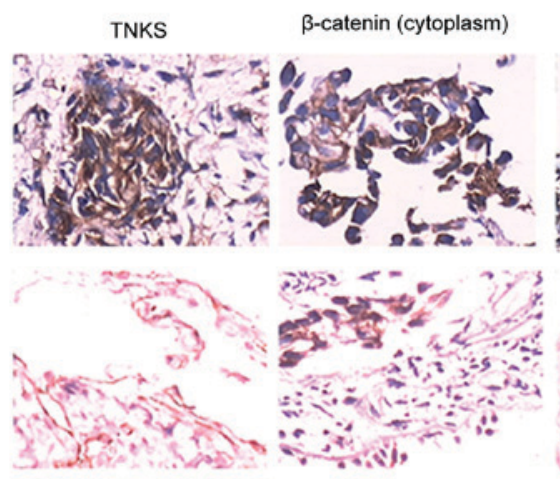

B

Lung

adenocarcinoma

group

Adjacent

group

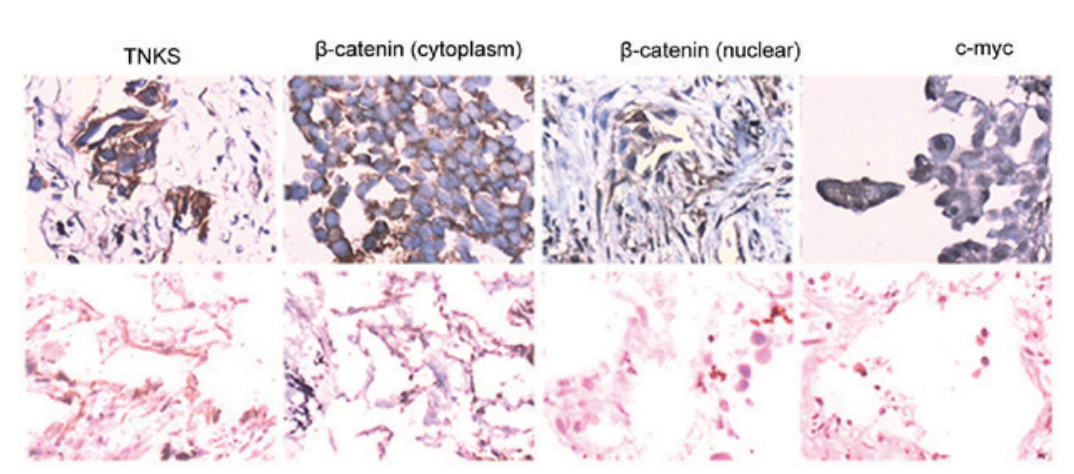

Figure 1. Expression of TNKS, $\beta$-catenin and c-Myc in lung adenocarcinoma and adjacent tissues (magnification, $x 400)$. The expression of TNKS, $\beta$-catenin, and c-Myc was detected by immunohistochemistry. (A and B) TNKS, $\beta$-catenin, and c-Myc proteins exhibited positive expression in lung adenocarcinoma tissue, which was higher than that found in the tissues adjacent to the carcinoma. TNKS, tankyrase; c-Myc, Myc proto-oncogene protein.

SPSS 17.0 software (SPSS, Inc., Chicago, IL, USA). Data counts in all cases were expressed as a percentage; a $\chi^{2}$ test was performed to compare between groups. The correlation between TNKS, $\beta$-catenin, and c-Myc expression were evaluated using the Spearman correlation coefficient. Comparative Student's unpaired t-test was used to assess the statistical significance between two groups. One-way analysis of variance was performed to statistically compare two or more groups. The post-hoc test used was Student-Newman-Keuls (SNK). $\mathrm{P}<0.05$ was considered to indicate a statistically significant difference.

\section{Results}

Expression of TNKS, $\beta$-catenin, and $c$-Myc in lung adenocarcinoma and adjacent carcinoma tissues. TNKS-positive immunostaining was identified by brown staining in the cytoplasm of tumor cells (Fig. 1A and B). $\beta$-catenin was mainly found in the cytoplasm and nucleus of the lung adenocarcinoma group, whereas it was expressed only in the cytoplasm of the paired adjacent carcinoma group (Fig. 1A and B). c-Myc was predominantly observed in the nucleus of cells belonging to the lung adenocarcinoma group (Fig. 1A and B). The positive expression of TNKS, c-Myc and $\beta$-catenin was significantly increased in the lung adenocarcinoma group compared with the paired adjacent group ( $\mathrm{P}<0.05$; Fig. 1 and Table II). The correlation between TNKS expression and other WNT-associated proteins was further investigated by comparing changes in TNKS expression levels to those of $\beta$-catenin and c-Myc, revealing a significant positive value (Table III). Western blot analysis was conducted to detect relative TNKS expression levels in 21 lung adenocarcinoma and paired adjacent carcinoma tissues. Representative blots of three paired samples demonstrate that TNKS expression is significantly higher in the lung adenocarcinoma group than in the paired adjacent carcinoma group ( $\mathrm{P}<0.05$; Fig. 2).

Protein expression of TNKS in three lung adenocarcinoma cell lines. Western blotting results (Fig. 3) demonstrated that TNKS protein expression levels in A549 cells were significantly higher than those in Calu-3 and SK-LU-1 cells $(\mathrm{P}<0.05$; Fig. 3). Owing to the higher TNKS protein expression levels observed in A549 cells compared with Calu-3 and SK-LU-1 cells, A549 cells were selected for subsequent experiments.

XAV939 inhibits the proliferation of A549 cells in vitro. To analyze the inhibitory effects of XAV939 at different concentrations $(0.1,0.5,1,5$ and $10 \mu \mathrm{mol} / \mathrm{l})$ on A549 cell proliferation, an MTT assay was performed at specific time points $(24,48,72$ and $96 \mathrm{~h})$. At all experimental time points, XAV939 treatment was able to significantly inhibit A549 cell proliferation compared with the control group $\left(\mathrm{F}_{24 \mathrm{~h}}=30.382\right.$, $\left.\mathrm{F}_{48 \mathrm{~h}}=52.463, \mathrm{~F}_{72 \mathrm{~h}}=56.635, \mathrm{~F}_{96 \mathrm{~h}}=59.274 ; \mathrm{P}<0.05\right)$, with the exception of the 5 -and $10-\mu \mathrm{mol} / 1$ groups at the $24 \mathrm{~h}$ time point $(\mathrm{P}=0.147)$.

XAV939 inhibits the proliferation of A549. Fig. 4 presents the values of inhibition of A490 proliferation at different XAV939 concentrations $(0.1,0.5,1,5$ and $10 \mu \mathrm{mol} / \mathrm{l})$ and different times $(24,48,72$ and 96 h). Between groups treated 
Table II. Expression of TNKS, $\beta$-catenin and c-Myc in lung adenocarcinoma and adjacent group.

\begin{tabular}{|c|c|c|c|c|c|}
\hline \multirow[b]{2}{*}{ Group } & \multirow[b]{2}{*}{ Total patients } & \multirow[b]{2}{*}{ TNKS, n (\%) } & \multicolumn{2}{|c|}{$\beta$-catenin expression } & \multirow[b]{2}{*}{ Positive c-Myc expression } \\
\hline & & & Cytoplasm & Nuclear & \\
\hline Adenocarcinoma, n (\%) & 72 & $65(90.28)$ & $64(88.89)$ & $51(70.83)$ & $48(66.67)$ \\
\hline Adjacent, n (\%) & 67 & $18(26.86)$ & $20(29.85)$ & $8(11.94)$ & $9(13.43)$ \\
\hline$\chi^{2}$ & & $58.01^{\mathrm{b}}$ & $50.588^{b}$ & $49.273^{b}$ & $40.66^{\mathrm{a}}$ \\
\hline
\end{tabular}

Expression assessed by immunohistochemistry. ${ }^{\mathrm{a}} \mathrm{P}<0.05$, ${ }^{\mathrm{b}} \mathrm{P}<0.01$. TNKS, tankyrase; c-Myc, Myc proto-oncogene protein.

Table III. Correlation between the expression of $\beta$-catenin, TNKS, and c-Myc proteins in 72 cases of lung adenocarcinoma.

\begin{tabular}{|c|c|c|c|c|c|c|}
\hline \multirow[b]{2}{*}{ Group } & \multicolumn{2}{|c|}{ TNKS expression, $\mathrm{n}$} & \multirow[b]{2}{*}{ R-value } & \multicolumn{2}{|c|}{ c-Myc expression, $\mathrm{n}$} & \multirow[b]{2}{*}{ R-value } \\
\hline & Positive & Negative & & Positive & Negative & \\
\hline \multicolumn{7}{|l|}{$\beta$-catenin (cytoplasm) } \\
\hline Negative expression & 5 & 3 & $0.682^{\mathrm{a}}$ & 1 & 7 & $0.814^{\mathrm{a}}$ \\
\hline Positive expression & 60 & 4 & & 47 & 17 & \\
\hline \multicolumn{7}{|l|}{$\beta$-catenin (nucleus) } \\
\hline Negative expression & 16 & 5 & $0.619^{\mathrm{a}}$ & 10 & 11 & $0.495^{\mathrm{a}}$ \\
\hline Positive expression & 49 & 2 & & 38 & 13 & \\
\hline
\end{tabular}

${ }^{\mathrm{a}} \mathrm{P}<0.05$. TNKS, tankyrase; c-Myc, Myc proto-oncogene protein.

A

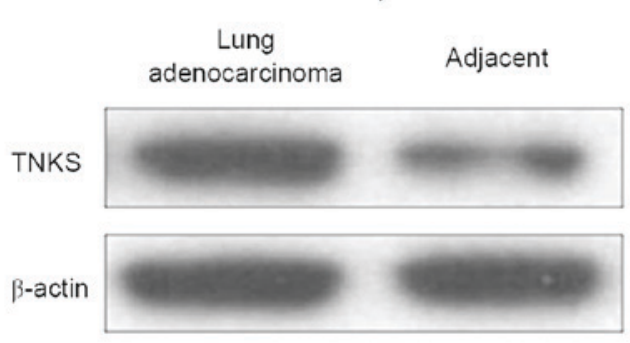

C

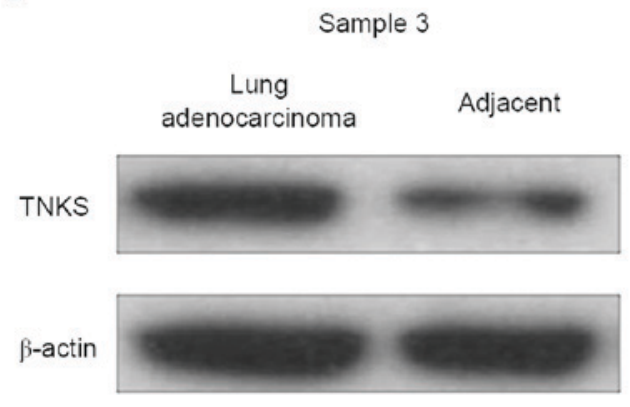

B

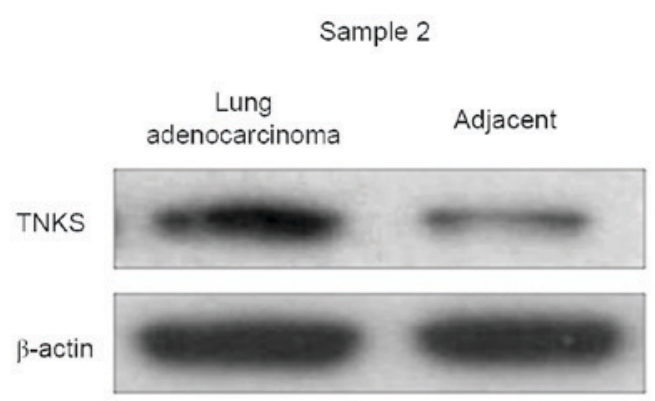

D

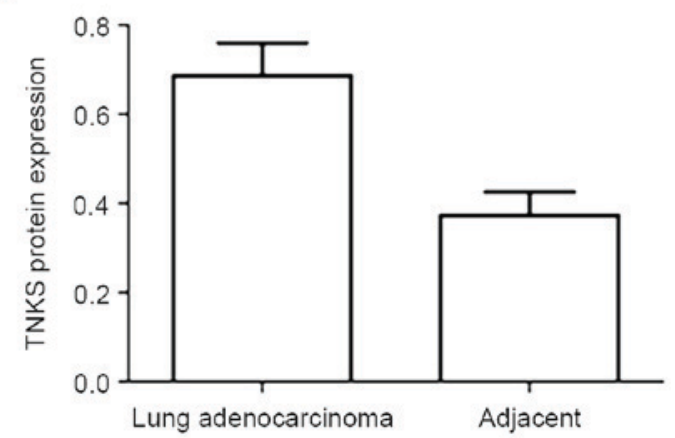

Figure 2. Expression of TNKS protein in (A) sample 1, (B) sample 2 and (C) sample 3 in lung adenocarcinoma and adjacent tissues, as detected by western blotting. (D) TNKS relative expression in 21 samples was significantly higher in the lung adenocarcinoma group compared with the adjacent-to-carcinoma group $\mathrm{P}<0.05$ vs. adjacent. TNKS, tankyrase.

with the same concentration of XAV939, the differences were statistically significant at the different time points tested $(\mathrm{P}<0.05)$, except the $0.1 \mu \mathrm{mol} / 1 \mathrm{XAV} 939$ treatment group. 
A

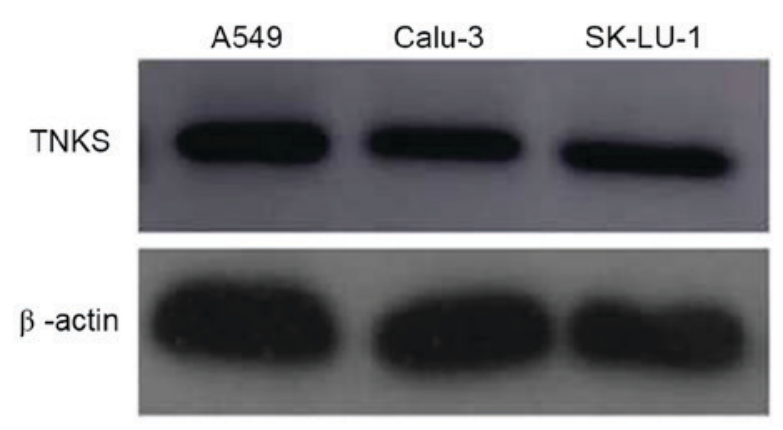

B

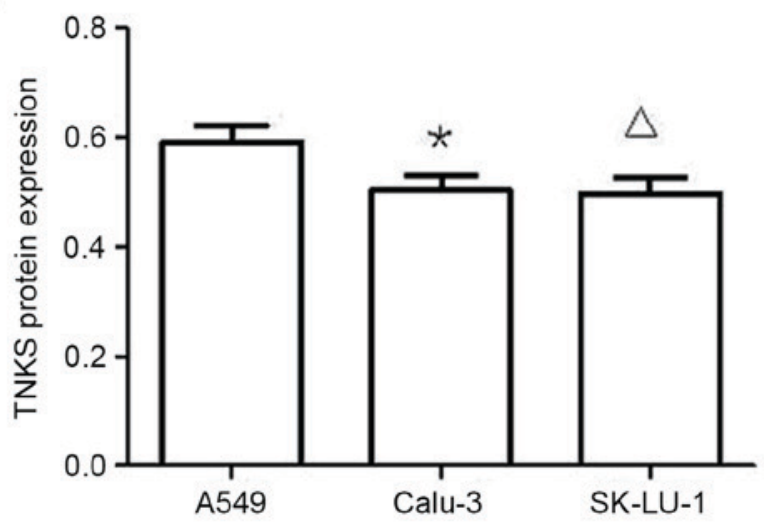

Figure 3. Expression of TNKS in three lung adenocarcinoma cell lines. (A) Western blot analysis and (B) quantification of this analysis demonstrated that the level of TNKS protein expression in A549 cells was significantly higher compared with that in Calu-3 and SK-LU-1 cells. ${ }^{*} \mathrm{P}<0.05$, A549 vs. Calu-3, ${ }^{\Delta} \mathrm{P}<0.05$, A549 vs. SK-LU-1 cells. TNKS, tankyrase.

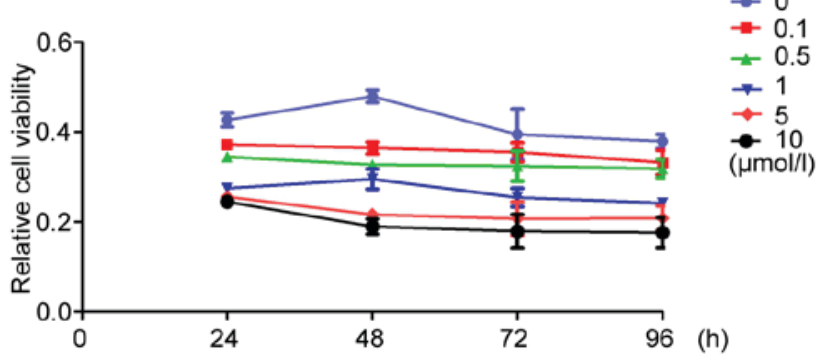

Figure 4. MTT assays. A549 cells were treated with increasing concentration of XAV939 $(0.1,0.5,1,5$ and $10 \mu \mathrm{M})$ for $24,4,72$ and $96 \mathrm{~h}$. The result was shown as relative cell viability per concentration at each time point.

The SNK test revealed that the differences were statistically significant at the different time points ( 24 vs. $48 \mathrm{~h}, 24$ vs. 72 h, 24 vs. 96 h, 48 vs. 72 h and 72 vs. 96 h) at the same concentration of XAV939.

XAV939 inhibits the clonogenicity of A549 cells. Treatment of the A549 cell line, plated under colony forming conditions, with $0.1,1$ and $10 \mu \mathrm{mol} / 1$ of XAV939, significantly inhibited colony formation ability compared with cells under control treatment, as shown with colony number quantification (Fig. 5).

XAV939 inhibits the migration of A549 cells in vitro. To assess whether XAV939 treatment inhibited A549 cell migration in vitro, the results of the wound-healing assay (Fig. 6) demonstrated that the wound width in groups treated with 0.1 , $0.5,1,5$ and $10 \mu \mathrm{mol} / 1$ XAV939 was $165.8 \pm 12.3,176.6 \pm 11.9$, $267.4 \pm 13.5,328.7 \pm 18.1$ and $445.4 \pm 21.6 \mu \mathrm{m}$, respectively.

These gaps were all significantly wider than that in the control group $(106.4 \pm 10.5 \mu \mathrm{m}, \mathrm{P}<0.5)$, demonstrating that the cell migratory ability was decreased. When comparisons within different treatment groups were performed, the differences were statistically significant $(\mathrm{F}=786.294 ; \mathrm{P}<0.05)$ other than for the 0.1 and $0.5 \mu \mathrm{mol} / 1$ groups $(\mathrm{P}>0.05)$. These results revealed that XAV939 was able to inhibit the migration of A549 cells in a concentration-dependent manner. $\beta$-catenin mRNA expression. The results of RT-sqPCR demonstrated that $\beta$-catenin (Fig. 7) and c-Myc (Fig. 8) mRNA expression were significantly downregulated in 0.1 , 1 and $10 \mu \mathrm{mol} / 1 \mathrm{XAV} 939$ treatment groups compared with the control group $(\mathrm{P}<0.05)$. The expression of $\mathrm{c}-\mathrm{Myc}$ was demonstrated to be significantly different between treatment groups, $0.1,1$ and the $10 \mu \mathrm{mol} / 1$ group $(\mathrm{P}<0.05)$. However, the differences in $\beta$-catenin expression were not statistically significant between the 0.1 and the $1 \mu \mathrm{mol} / 1$ groups $(\mathrm{P}>0.05)$.

Immunofluorescence. The localization of $\beta$-catenin expression, as observed by immunofluorescence, revealed that the protein had a tendency to translocate to the cytoplasm/membrane from the cytoplasm/nucleus (Fig. 9); this translocation was directly proportional to the concentration of XAV939 used.

Western blotting. Analysis by western blotting (Fig. 10) demonstrated that the level of $\beta$-catenin, TNKS, and c-Myc protein expression in A549 cells treated with XAV939 or DDP was significantly reduced compared with the control group $(\mathrm{P}<0.05)$. However, the combined effect of the two drugs further attenuated the inhibitory effect of each drug when used alone $(\mathrm{P}<0.05)$.

\section{Discussion}

The majority of patients with lung cancer frequently develop tumor metastasis and relapse shortly following surgery, radiotherapy, or chemotherapy (13). The 5-year relative survival rate is only $17 \%(13)$. WNT/ $\beta$-catenin signaling is part of a functional network present in the first metazoans and is implicated in a broad range of biological functions, which are fundamental in stem cells, embryonic development and adult organs (14). Deregulation of components of the WNT/ $\beta$-catenin signaling pathway has been implicated in a wide spectrum of diseases, including several types of cancer (14). In lung adenocarcinoma, the frequently upregulated $\mathrm{WNT} / \beta$-catenin signaling pathway represents a promising target for molecular therapies. Currently, multiple key factors belonging to the WNT/ $\beta$-catenin signaling cascade represent potential therapeutic targets (15). Previous research has confirmed 
A
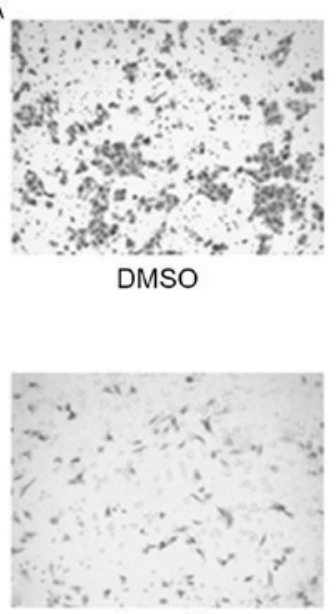

$1 \mu \mathrm{mol} / \mathrm{l}$

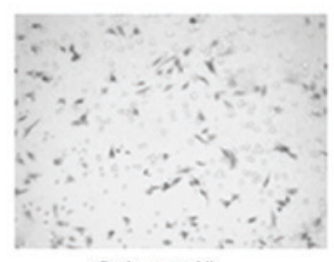

$0.1 \mu \mathrm{mol} / \mathrm{l}$

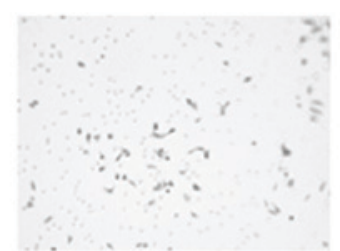

$10 \mu \mathrm{mol} / \mathrm{l}$
B

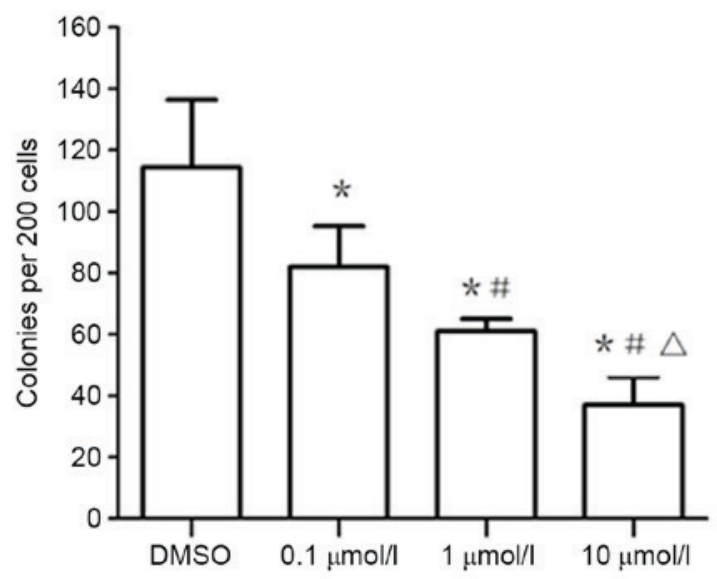

Figure 5. (A) XAV939 inhibits the clonogenicity of A549 cells in vitro. (B) Treatment of the A549 cell line with $0.1,1$ and $10 \mu$ mol/1 XAV939 significantly inhibited colony formation compared with the control. ${ }^{*} \mathrm{P}<0.05$ vs. the control group; ${ }^{*} \mathrm{P}<0.05$ vs. $0.1 \mu \mathrm{mol} / 1 \mathrm{XAV} 939 ;{ }^{\Delta} \mathrm{P}<0.05 \mathrm{vs} .1 \mu \mathrm{mol} / 1 \mathrm{XAV} 939$.

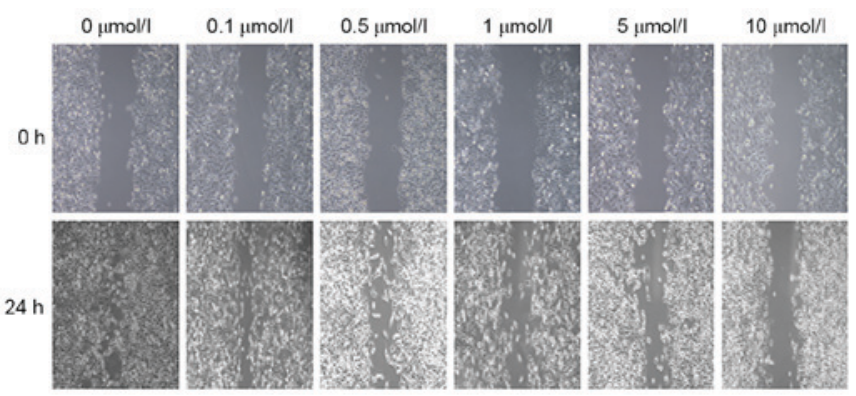

Figure 6. Effect of XAV939 on A549 cell migration was detected via wound-healing assay. The wound widths in the different XAV939 treatmen groups $(0.1,0.5,1,5,10 \mu \mathrm{mol} / 1)$ after $24 \mathrm{~h}$ were all significantly wider than those of the control group (magnification, $\mathrm{x} 200$ ).
A

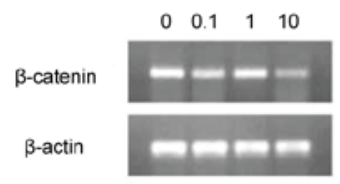

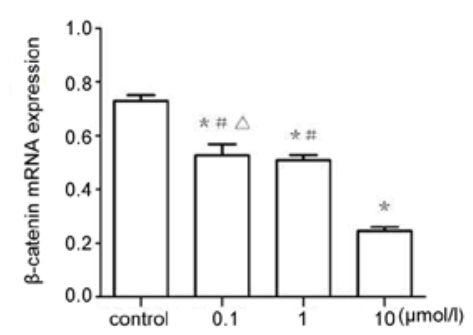

Figure 7. $\beta$-catenin mRNA expression at different XAV939 concentrations as detected by RT-sqPCR. (A) RT-PCR gel (B) and relative expression of $\beta$-catenin mRNA in A549 cells, treated with different XAV939 concentrations. ${ }^{*} \mathrm{P}<0.05$ vs. the control group; ${ }^{\#} \mathrm{P}<0.05$ vs. $10 \mu \mathrm{mol} / 1 \mathrm{XAV} 939 ;{ }^{\Delta} \mathrm{P}>0.05$ vs. $1 \mu \mathrm{mol} / 1 \mathrm{XAV} 939$. RT-sqPCR, reverse transcription-semi-quantitative polymerase chain reaction.

that multiple physiological and pathological processes that are activated by WNT signals are regulated by TNKS and its corresponding inhibitors $(8,16,17)$.

The data from the present study revealed that TNKS and $\beta$-catenin expression was increased in lung adenocarcinoma tissue, and were also positively correlated. However, $\beta$-catenin is a target of the WNT signaling pathway, and we hypothesize that enhanced TNKS expression levels are associated with the
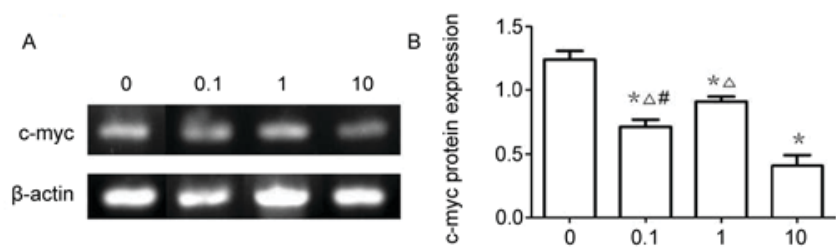

Figure 8. c-Myc mRNA expression at different XAV939 concentrations as detected by RT-sqPCR. (A) RT-PCR gel (B) and relative expression of $\beta$-catenin mRNA in A549 cells, treated with different XAV939 concentrations. ${ }^{*} \mathrm{P}<0.05$ vs. control group; ${ }^{\circ} \mathrm{P}<0.05$ vs. $10 \mu \mathrm{mol} / 1 \mathrm{XAV} 939 ;{ }^{\#} \mathrm{P}<0.05$ vs. $1 \mu \mathrm{mol} / 1 \mathrm{XAV} 939 . \mathrm{c}-\mathrm{Myc}, \mathrm{Myc}$ proto-oncogene protein; RT-sqPCR, reverse transcription-semi-quantitative polymerase chain reaction.

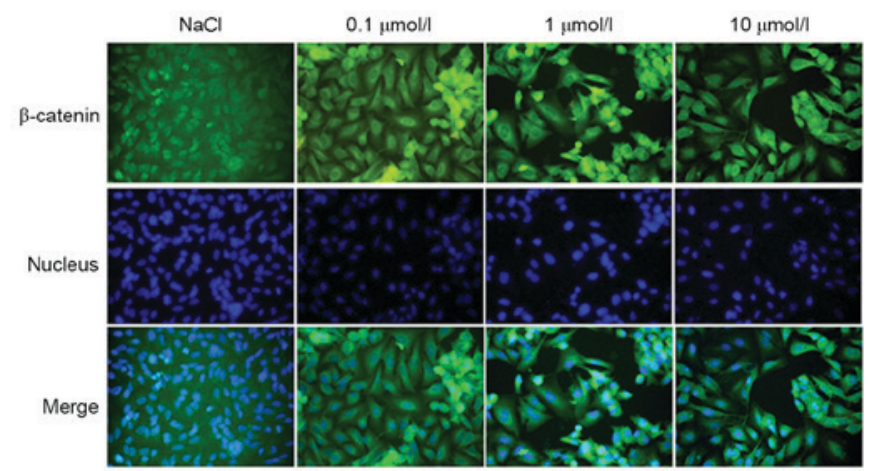

Figure 9. Localization of $\beta$-catenin immunofluorescence in response to treatment with $\mathrm{NaCl}$ (control), $0 ., 1$ and $10 \mu \mathrm{mol} / 1$ XAV939 in A549 cells (magnification, $\mathrm{x} 400$ ).

abnormal activation of the WNT signaling pathway. XAV939 is a small molecule that selectively inhibits TNKS, and also inhibits the transcription of $\beta$-catenin. Using XAV939 to inhibit the WNT pathway is a therapeutic strategy used for the treatment of several types of cancer (18-20). In the breast cancer MDA-MB-231 cell line, inhibition of TNKS1 was revealed to weaken cell migration, induced by WNT3a (11). Tian et al (21) demonstrated that TNKS1 inhibition may, in part, block the 

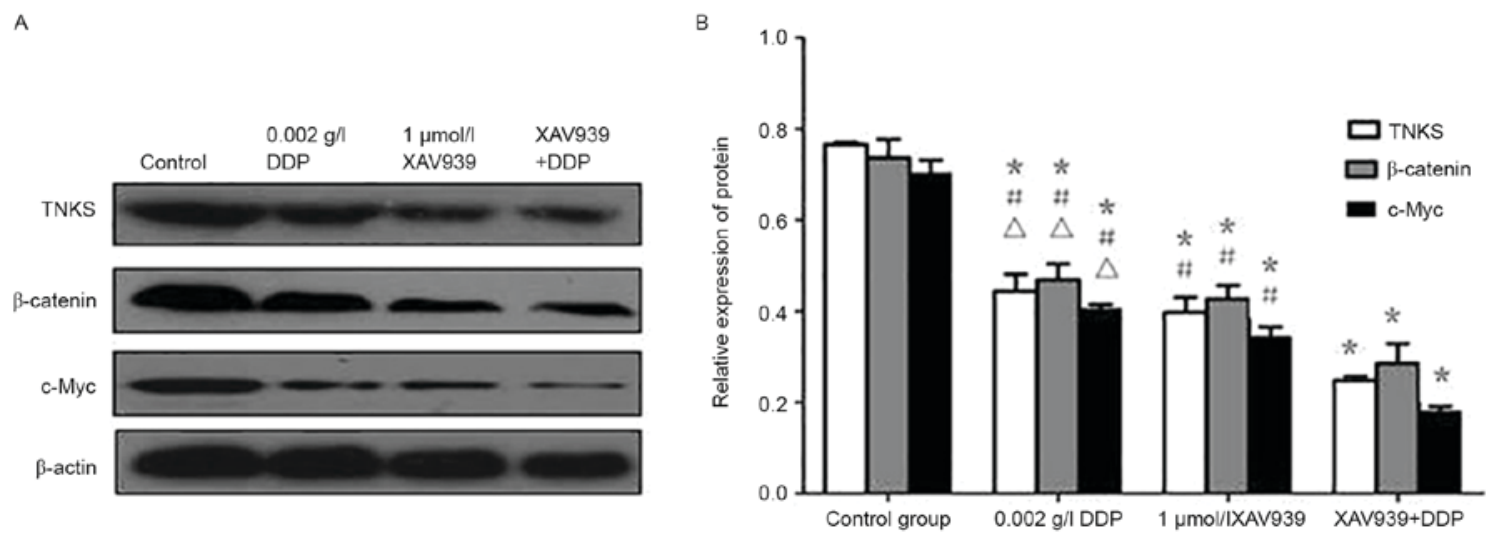

Figure 10. (A) Expression of $\beta$-catenin, TNKS, and c-Myc protein as detected by western blotting. (B) Quantification of western blotting results. "P $<0.05$ vs. control group; ${ }^{~} \mathrm{P}<0.05$ vs. XAV939+DDP group; ${ }^{\Delta} \mathrm{P}>0.05$ vs. XAV939 group. TNKS, tankyrase; c-Myc, Myc proto-oncogene protein; DDP, cisplatin.

WNT/ $\beta$-catenin signaling cascade and reduce the expression of anti-apoptotic proteins. In addition, it was further demonstrated that TNKS1 inhibition decreased in vitro colony formation. De la Roche et al (22) demonstrated that TNKS inhibitors also inhibited WNT-induced transcription, and reduced $\beta$-catenin transcriptional activity in colorectal cancer cells. Busch et al (7) revealed that knockdown of TNKS1 and/or TNKS2 with small interfering RNAs or short hairpin RNAs reduced lung cancer cell proliferation and repressed tumor formation in murine xenograft and syngeneic lung cancer models. The present study provides initial evidence to support the notion that TNKS enzymes, in association with WNT/ $\beta$-catenin signaling components, are feasible targets for lung adenocarcinoma treatment.

The data from the present study indicated that high TNKS expression was more frequently detected in the lung adenocarcinoma group (90.28\%) than in the adjacent to carcinoma group (26.86\%). In addition, TNKS expression level was demonstrated to be significantly higher in tumor cells in the lung adenocarcinoma group compared with the control group, indicating that TNKS in lung adenocarcinoma is highly expressed. Aberrant WNT signaling caused by mutations in the $\beta$-catenin gene, a key regulator of the canonical WNT-signaling pathway, is frequently detected in lung cancer $(23,24)$. However, the mechanisms underlying the aberrant activation of WNT/ $\beta$-catenin signaling in lung cancer have not yet been fully characterized.

In the present study, lung adenocarcinoma cancer cells were observed to consistently express high levels of nuclear and cytoplasmic $\beta$-catenin protein (70.83 and $88.89 \%$, respectively). By contrast, $\beta$-catenin was predominantly expressed in the cytoplasm, with a small proportion in the nucleus in the adjacent-to-carcinoma group (29.85 and $11.94 \%$, respectively). The correlation between TNKS and WNT/ $\beta$-catenin signal was confirmed by comparing the level of $\beta$-catenin (nuclear) expression. (TNKS vs. $\beta$-catenin, $r=0.619, \mathrm{P}<0.05$; $\mathrm{c}-\mathrm{Myc}$ vs. $\beta$-catenin, $r=0.495, P<0.05)$. $\beta$-catenin is an oncoprotein that is normally localized in the cytoplasm (18). The results of the present study revealed that oncogenic WNT signals promote the cytosolic accumulation of $\beta$-catenin and nuclear translocation, leading to the activation of downstream targets, including the oncogene c-Myc, which is consistent with a previous report by Zhang et al (25). TNKS inhibition attenuates WNT/ $\beta$-catenin signaling by promoting dynamic assemblies of functional active destruction complexes into a TNKS-containing scaffold, even in the presence of an adenomatous polyposis coli (APC) truncation (26). Wang et al (9) demonstrated that XAV939 significantly inhibited the activation of $\mathrm{WNT} / \beta$-catenin signaling and attenuated bleomycin-induced lung fibrosis in mice, thus improving the survival of mice with lung injury.

Using cell viability and colony formation assays, it was revealed that XAV939 inhibited the proliferation and colony formation ability of A549 cells in vitro. The results of the wound-healing assay revealed the inhibitory effect of treatment with XAV939 on the migration of A549 cells in a dose-dependent manner. Taken together, these results demonstrated that XAV939 inhibited the proliferative, colony formation and migratory capacity of A549 cells.

$\beta$-catenin is a key molecule in the WNT pathway; its stable accumulation in the cytoplasm and translocation into the nucleus are critical events in this pathway. In normal cells, $\beta$-catenin is mainly located in the membrane. Once $\beta$-catenin accumulates in the cytoplasm, it is be translocated into the nucleus and binds with T-cell factor/lymphoid enhancer factor to induce transcription factors responsible for the transcription of target genes involved in the activation and regulation of cell proliferation and differentiation (27). Thus, the abnormal activation of the WNT pathway induces tumorigenesis (28). The RT-sqPCR data demonstrated that, compared with the control group, $\beta$-catenin and c-Myc expression in XAV939 treatment groups $(0.1,1$ and $10 \mu \mathrm{mol} / \mathrm{l})$ clearly decreased. Additionally, following treatment with $10 \mu \mathrm{mol} / 1$ XAV939 for $24 \mathrm{~h}$, the expression of $\beta$-catenin mRNA was significantly lower than that of other treatment groups. Immunofluorescence analysis demonstrated that $\beta$-catenin had a tendency to translocate from the cytoplasm/nucleus to the cytoplasm/membrane, depending on the dose-dependent groups $(0,0.1,1$ and $10 \mu \mathrm{mol} / \mathrm{l}$ ). Therefore, it was concluded that XAV939 might induce $\beta$-catenin degradation and inhibit its accumulation in the cytoplasm, leading to a weakening or inhibition of the abnormal activation of the WNT signaling pathway. This may potentially be a mechanism through which XAV939 inhibits A549 cell proliferation and migration.

DDP is used as a first-line drug for the treatment of advanced non-small cell lung cancer. However, the drug is usually prescribed at a low dosage owing to its toxicity. In the 
present study, the expression level of $\beta$-catenin, TNKS and c-Myc proteins was detected by western blotting. A549 cells treated with XAV939 or DDP exhibited decreased the expression of TNKS protein compared with untreated control cells. c-Myc, a downstream target of $\beta$-catenin, was also downregulated. In addition, the effect of combined XAV939 and DDP treatment decreased the expression of TNKS, $\beta$-catenin and c-Myc protein to a greater degree than when either drug was used alone. This result highlighted the potential utility of combination therapy in increasing the attenuation of the WNT/ $\beta$-catenin signaling pathway. The results of the present study indicate that XAV939 could be considered as a novel therapeutic agent for the treatment of lung cancer. XAV939 may also improve the curative effect of DDP and reduce adverse reactions.

In summary, the present study revealed that TNKS and $\beta$-catenin expression levels were increased in lung adenocarcinoma tissue and were positively correlated with each other. Thus, it can be concluded that the enhanced expression level of TNKS is associated with the abnormal activation of the WNT signaling pathway. The WNT/ $\beta$-catenin pathway is considered a particularly difficult target for molecular interventions owing to its numerous non-evident enzyme targets, which may disrupt necessary and beneficial biological processes (29). To the best of our knowledge, this is the first study to reveal the effect of the TNKS inhibitor XAV939 on the WNT/ $\beta$-catenin signaling pathway in lung adenocarcinoma; TNKS inhibitors should thereby reduce $\beta$-catenin levels and activity. As such, TNKS enzymes represent promising candidate targets for anticancer molecular therapies (30). The present study provides experimental evidence for the basis of novel therapeutic strategies for the clinical treatment of lung cancer. Future studies are required to delineate further this mechanism and its role in suppressing lung tumor progression in vivo.

\section{Acknowledgements}

The authors would like to thank Dr Shiwu Zhang (Tianjin People's Hospital, Tianjin, China) for assistance with the experiments and valuable discussion.

\section{Funding}

The present study was supported by National Natural Science Foundation (grant no. 81774054).

\section{Availability of data and materials}

The datasets used and/or analyzed during the current study are available from the corresponding author on reasonable request.

\section{Authors' contributions}

CL contributed substantially to the conception and design of the study, and acquisition of data. XZ performed the immunohistochemical experiments and was a major contributor in writing the manuscript. YH performed the western blot analysis, reverse transcription-polymerase chain reaction examination and analysis and interpretation of data. YL was responsible for pathological diagnosis and image analysis. FL contributed to cell culture and data collection. JZ produced the paraffin sections and performed some cellular functional tests. All authors read and approved the final manuscript.

\section{Ethics approval and consent to participate}

The use of the tissue samples for this study was approved by the First Teaching Hospital of Tianjin University of Traditional Chinese Medicine Medical Ethics Committee (Tianjin, China). Ethical lot number: TYLL2018 [K] character005.

\section{Consent for publication}

Identifying information, including names, initials, date of birth or hospital numbers, images or statements were not included in the present study.

\section{Competing interests}

The authors have declared that there are no competing interests.

\section{References}

1. Zahir ST and Mirtalebi M: Survival of patients with lung cancer, Yazd, Iran. Asian Pac J Cancer Prev 13: 4387-4391, 2012.

2. Cancer Genome Atlas Research Networ: Comprehensive molecular profiling of lung adenocarcinoma. Nature 511: 543-550, 2014 .

3. Liu ZL, Jin BJ, Cheng CG, Zhang FX, Wang SW, Wang Y and Wu B: Apatinib resensitizes cisplatin-resistant non-small cell lung carcinoma A549 cell through reversing multidrug resistance and suppressing ERK signaling pathway. Eur Rev Med Pharmacol Sci 21: 5370-5377, 2017.

4. Holland JD, Klaus A, Garratt AN and Birchmeier W: Wnt signaling in stem and cancer stem cells. Curr Opin Cell Biol 25: $855-863,2013$.

5. Anastas JN and Moon RT: WNT signalling pathways as therapeutic targets in cancer. Nat Rev Cancer 13: 11-26, 2013.

6. McGonigle S, Chen Z, Wu J, Chang P, Kolber-Simonds D, Ackermann K, Twine NC, Shie JL, Miu JT, Huang KC, et al: E7449: A dual inhibitor of PARP1/2 and tankyrase1/2 inhibits growth of DNA repair deficient tumors and antagonizes Wnt signaling. Oncotarget 6: 41307-41323, 2015.

7. Busch AM, Johnson KC, Stan RV, Sanglikar A, Ahmed Y, Dmitrovsky E and Freemantle SJ: Evidence for tankyrases as antineoplastic targets in lung cancer. Bmc Cancer 13: 211, 2013.

8. Kulak O, Chen H, Holohan B, Wu X, He H, Borek D, Otwinowski Z, Yamaguchi K, Garofalo LA, Ma Z, et al: Disruption of Wnt $/ \beta$-catenin signaling and telomeric shortening are inextricable consequences of tankyrase inhibition in human cells. Mol Cell Biol 35: 2425-2435, 2015.

9. Wang C, Zhu H, Sun Z, Xiang Z, Ge Y, Ni C, Luo Z, Qian W and Han $X$ : Inhibition of Wnt $/ \beta$-catenin signaling promotes epithelial differentiation of mesenchymal stem cells and repairs bleomycin-induced lung injury. Am J Physiol Cell Physiol 307: C234-C244, 2014.

10. Kamal A, Riyaz S, Srivastava AK and Rahim A: Tankyrase inhibitors as therapeutic targets for cancer. Curr Top Med Chem 14: 1967-1976, 2014.

11. Casás-Selves M, Kim J, Zhang Z, Helfrich BA, Gao D, Porter CC, Scarborough HA, Bunn PA Jr, Chan DC, Tan AC and DeGregori J: Tankyrase and the canonical Wnt pathway protect lung cancer cells from EGFR inhibition. Cancer Res 72: 4154-4164, 2012.

12. Arqués O,Chicote I,Puig I, Tenbaum SP, Argilés G, Dienstmann R, Fernández N, Caratù G, Matito J, Silberschmidt D, et al: Tankyrase inhibition blocks Wnt/ $\beta$-catenin pathway and reverts resistance to PI3K and AKT inhibitors in the treatment of colorectal cancer. Clin Cancer Res 22: 644-656, 2016.

13. Siegel R, Naishadham D and Jemal A: Cancer statistics, 2013. CA Cancer J Clin 63: 11-30, 2013. 
14. Voronkov A and Krauss S: Wnt/beta-catenin signaling and small molecule inhibitors. Curr Pharm Des 19: 634-664, 2013.

15. Polakis P: Drugging Wnt signalling in cancer. EMBO J 31: 2737-2746, 2012.

16. Huang SM, Mishina YM, Liu S, Cheung A, Stegmeier F, Michaud GA, Charlat O, Wiellette E, Zhang Y, Wiessner S, et al: Tankyrase inhibition stabilizes axin and antagonizes WNT signaling. Nature 461: 614-620, 2009.

17. Wu X, Luo F, Li J, Zhong X and Liu K: Tankyrase 1 inhibitior XAV939 increases chemosensitivity in colon cancer cell lines via inhibition of the Wnt signaling pathway. Int J Oncol 48: 1333-1340, 2016.

18. Clevers $\mathrm{H}$ and Nusse $\mathrm{R}: \mathrm{Wnt} / \beta$-catenin signaling and disease. Cell 149: 1192-1205, 2012.

19. Lecarpentier Y, Claes V, Duthoit G and Hébert JL: Circadian rhythms, Wnt/beta-catenin pathway and PPAR alpha/gamma profiles in diseases with primary or secondary cardiac dysfunction. Front Physiol 5: 429, 2014.

20. Dregalla RC, Zhou J, Idate RR, Battaglia CL, Liber HL and Bailey SM: Regulatory roles of tankyrase 1 at telomeres and in DNA repair: Suppression of T-SCE and stabilization of DNA-PKcs. Aging (Albany NY) 2: 691-708, 2010.

21. Tian XH, Hou WJ, Yan F, Fan J, Tong H, Bai SL, Chen Q, $\mathrm{Xu} \mathrm{H}$ and Li Y: XAV939, a tankyrase 1 inhibitior, promotes cell apoptosis in neuroblastoma cell lines by inhibiting Wnt/ $\beta$-catenin signaling pathway. J Exp Clin Cancer Res 32: $100,2013$.

22. de la Roche M, Ibrahim AE and Mieszczanek J, Bienz M: LEF1 and B9L shield $\beta$-catenin from inactivation by Axin, desensitizing colorectal cancer cells to tankyrase inhibitors. Cancer Res 74: 1495-1505, 2014.
23. Chen X, Meng J, Yue W, Yu J, Yang J, Yao Z and Zhang L: Fibulin-3 suppresses Wnt/ $\beta$-catenin signaling and lung cancer invasion. Carcinogenesis 35: 1707-1716, 2014.

24. Lim JH, Park JW and Chun YS: Human arrest defective 1 acetylates and activates beta-catenin, promoting lung cancer cell proliferation. Cancer Res 66: 10677-10682, 2006.

25. Zhang X, Lou Y, Zheng X, Wang H, Sun J, Dong Q and Han B: Wnt blockers inhibit the proliferation of lung cancer stem cells. Drug Des Devel Ther 9: 2399-2407, 2015.

26. Thorvaldsen TE, Pedersen NM, Wenzel EM, Schultz SW, Brech A,Liestøl K, Waaler J, Krauss S and Stenmark H: Structure, dynamics and functionality of tankyrase inhibitor-induced degradasomes. Mol Cancer Res 13: 1487-1501, 2015.

27. Krishnamurthy $\mathrm{N}$ and Kurzrock R: Targeting the Wnt/beta-catenin pathway in cancer: Update on effectors and inhibitors. Cancer Treat Rev 62: 50-60, 2018.

28. Zhang X, Lou Y, Zheng X, Wang H, Sun J, Dong Q and Han B: Wnt blockers inhibit the proliferation of lung cancer stem cells. Drug Des Devel Ther 9: 2399-2407, 2015.

29. Kahn M: Can we safely target the WNT pathway? Nat Rev Drug Discov 13: 513-532, 2014.

30. Riffell JL, Lord CJ and Ashworth A: Tankyrase-targeted therapeutics: Expanding opportunities in the PARP family. Nat Rev Drug Discov 11: 923-936, 2012.

This work is licensed under a Creative Commons Attribution-NonCommercial-NoDerivatives 4.0 International (CC BY-NC-ND 4.0) License. 